Canadian

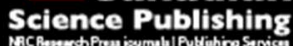

Applied Physiology, Nutrition, and Metabolism Physiologie appliquée, nutrition et métabolisme

\title{
Determination of the exercise intensity that elicits maximal fat oxidation in individuals with obesity
}

\begin{tabular}{|c|c|}
\hline Journal: & Applied Physiology, Nutrition, and Metabolism \\
\hline Manuscript ID & apnm-2016-0518.R2 \\
\hline Manuscript Type: & Article \\
\hline Date Submitted by the Author: & 23-Nov-2016 \\
\hline Complete List of Authors: & $\begin{array}{l}\text { Dandanell, Sune; University of Copenhagen, Center for Healthy Aging, } \\
\text { Department of Biomedical Sciences, Xlab; Metropolitan University College, } \\
\text { Department for Physiotherapy and Occupational Therapy } \\
\text { Præst, Charlotte; University of Copenhagen, Center for Healthy Aging, } \\
\text { Department of Biomedical Sciences, Xlab; Metropolitan University College, } \\
\text { Department for Physiotherapy and Occupational Therapy } \\
\text { Søndergård, Stine; University of Copenhagen, Center for Healthy Aging, } \\
\text { Department of Biomedical Sciences, Xlab } \\
\text { Skovborg, Camilla; University of Copenhagen, Center for Healthy Aging, } \\
\text { Department of Biomedical Sciences, Xlab } \\
\text { Dela, Flemming; University of Copenhagen, Center for Healthy Aging, } \\
\text { Department of Biomedical Sciences, Xlab; Bispebjerg University Hospital, } \\
\text { Department of Geriatrics } \\
\text { Larsen, Steen; University of Copenhagen, Center for Healthy Aging, } \\
\text { Department of Biomedical Sciences, Xlab } \\
\text { Helge, Jørn; University of Copenhagen, Center for Healthy Aging, } \\
\text { Department of Biomedical Sciences, Xlab }\end{array}$ \\
\hline Keyword: & $\begin{array}{l}\text { obesity < obesity, fat metabolism < metabolism, exercise metabolism < } \\
\text { metabolism, exercise intensity }<\text { exercise, lipid metabolism }\end{array}$ \\
\hline
\end{tabular}

\section{SCHOLARONE ${ }^{n}$ \\ Manuscripts}




\section{Determination of the exercise intensity that elicits maximal fat oxidation in}

\section{individuals with obesity}

Sune Dandanell ${ }^{1,2}$, Charlotte Boslev Præst ${ }^{1,2}$, Stine Dam Søndergård ${ }^{1}$, Camilla Skovborg ${ }^{1}$, Flemming

Dela $^{1,3}$, Steen Larsen ${ }^{1}$, Jørn Wulff Helge ${ }^{1}$

${ }^{1}$ Center for Healthy Aging, Department of Biomedical Sciences, Xlab, University of Copenhagen, Denmark

${ }^{2}$ Department for Physiotherapy and Occupational Therapy, Metropolitan University College, Copenhagen, Denmark.

${ }^{3}$ Department of Geriatrics, Bispebjerg University Hospital, Copenhagen, Denmark.

\section{Correspondence:}

Sune Dandanell

Department of Biomedical Science, Faculty of Health Science

Blegdamsvej 3, DK-2200 Copenhagen N, Denmark

Phone: + 45353275 06, Fax: + 45353274 20, E-mail: sunedj@sund.ku.dk

Co-author emails:

Charlotte Præst: c boslev@hotmail.com

Stine Dam Søndergård: ssoendergaard@sund.ku.dk

Camilla Skovborg casko@dong.dk

Flemming Dela: $\underline{\text { fdela@sund.ku.dk }}$

Steen Larsen: stelar@sund.ku.dk

Jørn Wulff Helge: jhelge@sund.ku.dk 


\section{Abstract}

Maximal fat oxidation (MFO) and the exercise intensity that elicits MFO (Fat Max $_{\text {) }}$ are commonly determined by indirect calorimetry during graded exercise tests in both obese and normal weight individuals. However, no protocol has been validated in individuals with obesity. Thus, the aims were to develop a graded exercise protocol for determination of Fat $\mathrm{Max}_{\mathrm{i}}$ in individuals with obesity, and to test validity and inter-method reliability. Fat oxidation was assessed over a range of exercise intensities in 16 individuals (Age: 28 (26-29) years, BMI: $\left.36(35-38) \mathrm{kg} \mathrm{m}^{-2}\right)(95 \% \mathrm{Cl})$ on a cycle ergometer. The graded exercise protocol was validated against a short continuous exercise (SCE) protocol, in which Fat $_{\text {Max }}$ was determined from fat oxidation at rest and during 10-min continuous exercise at 35, 50 and $65 \%$ of maximal oxygen uptake $\left(\mathrm{VO}_{2 \mathrm{max}}\right)$. Intraclass and Pearson correlation coefficients between the protocols were 0.75 and 0.72 and within subject coefficient of variation (CV) was 5 (3-7)\%. A Bland Altman plot revealed a bias of $-3 \%$ points of $\mathrm{VO}_{2 \max }$ (Limits of Agreement: -12 to 7 ). A tendency towards a systematic difference $(p=0.06)$ was observed, where Fat ${ }_{\text {Max }}$ occurred at $42(40-44)$ and 45 (43-47)\% of $\mathrm{VO}_{2 \max }$ with the graded and the SCE protocol, respectively. In conclusion, there was a high-excellent correlation and a low CV between the two protocols, suggesting that the graded exercise protocol has a high inter-method reliability. However, considerable intra-individual variation and a trend towards systematic difference between the protocols reveal that further optimization of the graded exercise protocol is needed to improve validity.

\section{Keywords}

Obesity, fat metabolism, exercise metabolism, lipid metabolism, exercise intensity 


\section{Introduction}

Maximal fat oxidation (MFO) and the exercise intensity eliciting MFO (Fat ${ }_{\text {Max }}$ ) varies with training status; well-trained individuals reach MFO at $45-65 \%$ of $\mathrm{VO}_{2 \max }$ (Achten et al. 2002; Achten and Jeukendrup 2003; Venables et al. 2005), whereas sedentary individuals reach MFO around 30-50\% of $\mathrm{VO}_{2 \max }$ (Venables et al. 2005; Venables and Jeukendrup 2008; Ara et al. 2011; Croci et al. 2013; Croci et al. 2014b). The concept of Fat $\mathrm{Max}_{\text {as }}$ as determined by indirect calorimetry during whole-body exercise was established in 2001 by Achten and colleagues (Achten et al. 2002), using a graded exercise protocol. Prior studies had measured fat oxidation during continuous exercise at two (Sidossis et al. 1997; Thompson et al. 1998), three (Romijn et al. 1993; Romijn et al. 2000) or four (Bergman and Brooks 1999) submaximal exercise intensities, hence Fat $_{\text {Max }}$ had until then not been accurately determined. Achten et al. concluded that their graded exercise protocol, commencing at 95 watt with increments of 35 watt every $3^{\text {rd }}$ minute, could be used for valid and reliable assessment of Fat ${ }_{\text {Max }}$ in well-trained individuals (Achten et al. 2002; Achten and Jeukendrup 2003). Day-to-day reliability of various graded exercise protocols for determination of Fat ${ }_{\text {Max }}$ was subsequently tested (Meyer et al. 2009; De Souza Silveira et al. 2016; Stoa et al. 2016) and excellent Pearson's (0.84-0.97) and intraclass correlations coefficients (ICC) (0.82-0.98) were reported. However, Bland-Altman plots revealed large intra-individual variation between test days (Meyer et al. 2009; Croci et al. 2014a).

The graded exercise protocol developed by Achten et al. was not designed for individuals with obesity and relatively poor aerobic capacity, and most likely this group of subjects will only complete 2-3 steps of the original test, hence Fat ${ }_{\text {Max }}$ will not be accurately determined. Consequently, various graded exercise protocols commencing at lower exercise intensities (30-50 watt) have been employed to determine Fat $_{\text {Max }}$ in obese (Van Aggel-Leijssen et al. 2002; Mogensen et al. 2009; Ara et al. 2011; 
Ipavec-Levasseur et al. 2015; Tan et al. 2016a). However, no protocol developed specifically for obese

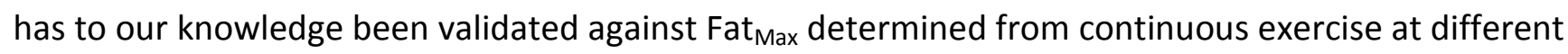
intensities.

Thus, the purpose of the present study was to develop, validate and inter-method reliability test a

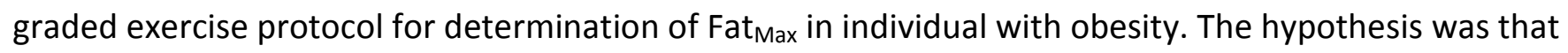
the protocol could accurately determine Fat $_{\text {Max. }}$

\section{Methods}

\section{Subjects}

Sixteen individuals with obesity (8/8 women/men, age: 28 (26-29) years, BMI: $\left.36(35-38) \mathrm{kg} \mathrm{m}^{-2}\right)(95 \%$

$\mathrm{Cl}$ ) participated in the study (Table 1), which was performed in accordance with the Helsinki declaration and approved by the local Research Ethics Committee, Copenhagen, Denmark (H-3-2013146). The subjects were informed orally and in writing about the experiments and potential risks before written consent were obtained. Exclusion criteria were cardiovascular and/or metabolic disease. One subject with obesity was excluded from the analyses as the subject was unable to complete the exercise tests. Menstrual cycle and use of oral contraceptives were not controlled for.

\section{Experimental design}

Graded exercise protocol

The 16 subjects with obesity performed a graded exercise protocol on an electronically braked cycle ergometer (Monark 834E, Vansbro, Sweden). The protocol started with a resting period of five min and was followed by six min warm-up at 30 watt. Then the intensity was increased every $3^{\text {rd }}$ min by 20 or 25 watt for women and men, respectively until the respiratory exchange ratio $(R E R)>1.0$. After a short break ( $2 \mathrm{~min}$ ) an incremental exercise protocol (2 min at 100 watt followed by increments of 20/25 
watt for women/men every $\mathrm{min}$ ) to voluntary exhaustion was initiated. A plateau in $\mathrm{VO}_{2 \max }$ (defined as a change of no more than $2 \mathrm{ml} \mathrm{kg}^{-1} \mathrm{~min}^{-1}$ with increasing work load) and RER $>1.15$ were used as criteria for achieving $\mathrm{VO}_{2 \max }$. Criteria for attainment of $\mathrm{VO}_{2 \max }$ in obese is discussed in Wood et al. (Wood et al. 2010). Heart rate (HR) was measured continuously over the test (RS400, Polar Electro OY, Kempele, Finland). Total duration of the protocol was $\sim 35$ min. including rest, warm-up, exercise periods and breaks.

Short continuous exercise protocol (SCE)

To verify if the results from the graded exercise protocol could be used to accurately determine Fat ${ }_{\text {Max }}$ in obese, fat oxidation at rest and during continuous exercise at 35,50 and $65 \%$ of $\mathrm{VO}_{2 \max }$ was determined during 10-min exercise periods on a separate day (2-7 days in between). A resting period of $10 \mathrm{~min}$ was followed by $10 \mathrm{~min}$ at $35 \%$ of $\mathrm{VO}_{2 \max }$, which also served as warm-up. The order of the two other exercise intensities ( 50 and $65 \%$ of $\mathrm{VO}_{2 \max }$ ) were randomized and the exercise periods were separated by rest periods of $45 \mathrm{~min}$ (subjects rested in the supine position). Ad libitum water, but no food was served in the breaks. Total duration was $2 \frac{1}{2}$ hours including rest and exercise periods. Day-to-day reliability of the graded exercise protocol Additionally, day-to-day reliability of the graded exercise protocol was tested in eight normal weight moderately trained subjects (3/5 women/men, age: 32 (30-34) years, BMI: 23 (22-24) kg m²), who performed the test on two different days (2-7 days in between). The graded exercise protocol was performed exactly as described for the individuals with obesity. No protocol has so far been validated and reliability tested in obese. The purpose of these additional tests was to allow comparison with graded exercise protocols developed for normal weight individuals.

\section{Measurements}


The subjects reported to the laboratory in the morning (between 8 and 10 a.m.) after an overnight fast (12h) on two different days (same time on both days). Body weight, height and waist circumference were measured. On the day of the graded exercise protocol a Dual-energy X-ray absorptiometry (DXA) scan (Lunar Prodigy Advance, Lunar, Madison, WI, USA) was performed to assess body composition. Resting blood pressure was measured in the seated position three times (interspersed by two min breaks) on the right upper arm (A\&D Medical, Tokyo, Japan). A resting blood sample was drawn from the antecubital vein on both test days, and additional blood samples were obtained right before initiation of the $10-$ min continuous exercise periods at 35,50 and $65 \%$ of $\mathrm{VO}_{2 \max }$, respectively. The additional blood samples were taken in order to retrospectively check plasma concentrations of glucose, insulin, lactate, free fatty acids (FFA) and glycerol. Oxygen uptake $\left(\mathrm{VO}_{2}\right)$, expired carbon dioxide $\left(\mathrm{VCO}_{2}\right)$ and pulmonary ventilation $\left(\mathrm{V}_{\mathrm{E}}\right)$ were measured continuously at rest and during exercise (Oxycon Pro, Jaeger, Würzburg, Germany).

\section{Control of diet and physical activity}

The subjects were told to eat identical diets the day before the two test days, and to abstain from any physical activity 48 hours before the tests. In line with previous studies determining Fat max $_{\text {(Achten et }}$ al. 2002; Tan et al. 2016b) a standardized 24-hour dietary questionnaire was used to evaluate the diet before the first test day, and the result was provided to the subjects hence they could repeat the diet before their second test day.

\section{Blood analysis}

Blood was sampled in iced glass tubes and immediately centrifuged at $2500 \mathrm{~g}$ at $4^{\circ} \mathrm{C}$ for $10 \mathrm{~min}$. The plasma fraction was collected and stored at $-80^{\circ} \mathrm{C}$ prior to analysis. Plasma insulin concentration was measured using an ELISA kit (Alpco, Salem, NH, USA) and plasma concentrations of glucose, lactate, 
FFA and glycerol were measured on an automated analyzer (COBAS 501, Roche, Mannheim, Germany) using standard assays. Hemoglobin concentration and hematocrit were analyzed immediately (Hemo Control Hemoglobin Analyzer, EKF Diagnostics, Magdeburg, Germany). HbA1c was analyzed on a DCA Vantage Analyzer (Siemens Healthcare, NY, USA).

\section{Data analysis}

$\mathrm{VO}_{2}, \mathrm{VCO}_{2}$ and $\mathrm{V}_{\mathrm{E}}$ data (sampling intervals of $10 \mathrm{sec}$ ) were averaged over the last $30 \mathrm{sec}$ of each step of the graded exercise protocol. To check whether steady-state was reached at each 3-min step of the graded exercise protocol $\mathrm{VO}_{2}$ and $\mathrm{VCO}_{2}$ obtained from 2.00-2.30 min was compared with $\mathrm{VO}_{2}$ and $\mathrm{VCO}_{2}$ obtained from 2.30-3.00 min (Supplementary Table S1). $\mathrm{VO}_{2}, \mathrm{VCO}_{2}$ and $\mathrm{V}_{\mathrm{E}}$ were averaged over the last five min during rest and of each 10 -min continuous exercise period. Fat oxidation rates were calculated using the stoichiometric equations described by Frayn (Frayn 1983), with the assumption that urinary nitrogen excretion was negligible. Fat oxidation rates at rest and during the graded exercise protocol and continuous exercise periods, respectively, were plotted against the relative exercise intensity (\% $\mathrm{VO}_{2 \mathrm{max}}$ ) and a $2^{\text {nd }}$ degree polynomial regression was used to determine Fat $\mathrm{Max}_{\text {and }} \mathrm{MFO}, \mathrm{VO}_{2}, \mathrm{~V}_{\mathrm{E}}, \mathrm{HR}$ and watt at Fat ${ }_{\text {Max }}$ for each subject individually. $A 3^{\text {rd }}$ degree polynomial regression was applied on fat

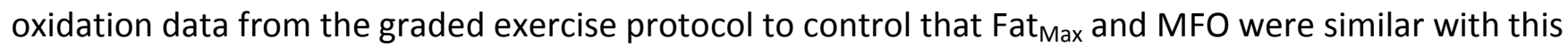
data analysis method.

\section{Statistics}

Data are presented as means $\pm 95 \% \mathrm{Cl}$ with significance set at an $\alpha$-level of 0.05 . Data were checked for normal distribution and equal variance. The inter-method reliability between the graded and the SCE protocol were analyzed with Pearson and intraclass correlation coefficients (ICC), and coefficient of variation (CV). Pearson correlation coefficient's and ICC's were interpreted as follows: $>0.75$ as 
excellent, $0.40-0.74$ as fair to high and $<0.40$ as poor (Fleiss 1986). Gender differences were analyzed with an unpaired t-test and systematic differences in Fat $\mathrm{Max}_{\text {and }} \mathrm{MFO}, \mathrm{VO}_{2}, \mathrm{VCO}_{2}, \mathrm{~V}_{\mathrm{E}}, \mathrm{HR}$ and Watt at Fat $_{\text {Max }}$ between the graded and the SCE protocol were analyzed with a paired t-test. The agreement

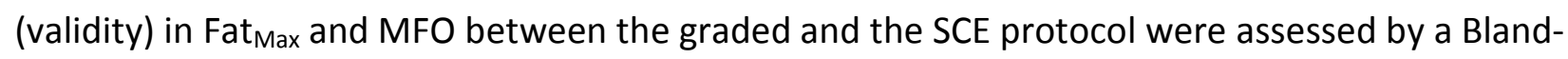
Altman plot establishing mean differences (bias) and $\pm 95 \%$ limits of agreement (LoA). Systematic differences in fasting levels of plasma FFA, glycerol, glucose, insulin and lactate were analyzed with a paired t-test, and possible differences in plasma concentrations of FFA, glycerol, glucose, insulin and lactate before initiation of each continuous exercise period was analyzed by a One-Way ANOVA with adjustment for multiple comparisons.

Additionally, day-to-day reliability of the graded exercise protocol was assessed in normal weight subjects (Pearson correlation coefficient and ICC, CV, systematic differences, bias and $\pm 95 \%$ LoA). Statistical analyses were performed in SAS Enterprise 4.3 (SAS Institutes, Cary, NC, USA) and figures were made in Graphpad Prism 6.01 Software Inc. (La Jolla, CA, USA).

\section{Results}

\section{Subject characteristics}

Obese women reached $\mathrm{Fat}_{\mathrm{Max}}$ at a higher $\%$ of $\mathrm{VO}_{2 \max }$ than obese males $(\mathrm{P}<0.05)$, during both the graded (45 (43-47) vs. 39 (37-40), respectively) and the SCE protocol (48 (47-50) vs. 40 (38-42), respectively). Obese women also reached a higher MFO (g $\mathrm{min}^{-1}$ ) compared to males during both the graded $(0.36(0.29-0.44)$ vs. $0.29(37-40)$, respectively) and the SCE protocol $(0.32(0.27-0.37)$ vs. 0.26 (0.21-0.31), respectively), albeit the latter was only borderline statistically significant $(P<0.10)$. From Figure $1 f$ and $2 f$ it appears that the intra-individual variation in Fat Max $_{\text {ax }}$ anF in women and men seem similar. 
Validity and inter-method reliability of the graded exercise protocol for determination of Fat Max $_{\text {in }}$ individuals with obesity

Fat oxidation, $\mathrm{VO}_{2}, \mathrm{VCO}_{2}$ and $\mathrm{V}_{\mathrm{E}}$ at each step of the graded and the SCE protocol are depicted in Figure 1a-d. Pearson's correlation coefficients and ICC's for Fat $\mathrm{Max}_{\text {ax }}$ and $\mathrm{VO}_{2}, \mathrm{VCO}_{2}, \mathrm{~V}_{\mathrm{E}}, \mathrm{HR}$ and Watt at Fat $\mathrm{Max}$ between the protocols were high-excellent for all variables (0.72-0.91) except from MFO, which was fair (0.48 and 0.56) (Table 2). Accordingly, CV's were $\leq 7 \%$ for all variables investigated except for MFO, which was $11 \%$. A Bland-Altman analysis of agreement between the protocols revealed a bias of $-3 \%$ points of $\mathrm{VO}_{2 \max }(95 \% \mathrm{LoA}-12$ to $7 \%)$ for Fat $\mathrm{Max}_{\text {and }}$ a.04 $\mathrm{g} \mathrm{min}^{-1}\left(95 \%\right.$ LoA -0.09 to $0.17 \mathrm{~g} \mathrm{~min}^{-1}$ ) for MFO, respectively (Figure 1e-f). A trend $(p=0.06)$ towards systematic difference between the graded and the SCE protocol in determination of Fat ${ }_{\text {Max }}$ was observed (Table 2). No systematic differences in fasting levels of plasma FFA, glycerol, glucose, insulin and lactate between the two test days were observed, and there was also no difference in the plasma milieu before initiation of exercise at 35, 50 and $65 \%$ of $\mathrm{VO}_{2 \max }$, respectively, in the SCE protocol (Table 3). Large intra-individual variation was, however, observed between the two test days in FFA and glycerol (Figure 19-h), which was also illustrated in within subjects CV's (Table 3).

\section{Day-to-day reliability of graded exercise protocol for determination of Fat Max $_{\text {in }}$ normal weight}

\section{subjects}

Fat oxidation, $\mathrm{VO}_{2}, \mathrm{VCO}_{2}$ and $\mathrm{V}_{\mathrm{E}}$ at each step of the two graded exercise tests are shown in Figure 2a-d. Pearson correlation coefficient and ICC's were excellent $(0.81-0.99)$ for all variables investigated except from MFO, which was fair (0.57-0.58). Within subjects CV's were low $(\leq 5 \%)$ for all variables except for MFO, which was high (11\%). A Bland-Altman analysis of the agreement between the two tests revealed a bias of $1 \%$ points of $\mathrm{VO}_{2 \max }\left(95 \% \mathrm{LoA}-8\right.$ to $11 \%$ points of $\mathrm{VO}_{2 \max }$ ) for Fat $\mathrm{Fax}_{\text {ax }}$ and $0.00 \mathrm{~g} \mathrm{~min}^{-1}$ (95 \% LoA 
-0.17 to $0.17 \mathrm{~g} \mathrm{~min}^{-1}$ ) for MFO (Figure $2 \mathbf{e}, \mathbf{f}$ ). No systematic differences in fasting levels of plasma FFA, glycerol, glucose, insulin and lactate between the two graded exercise tests were observed. Within subject CV's between the days were high (>14\%) for all variables except glucose, which was low (3\%) (Table 3).

\section{Discussion}

For the first time Fat $_{\text {Max }}$ determined with a graded exercise protocol developed specifically for individuals with obesity was validated and inter-method reliability tested against Fat Max $_{\text {determined }}$ from a SCE protocol. The main findings were a high to excellent ICC and Pearson correlation coefficient $(0.72$ and 0.75$)$ and a low within subject $C V(\leq 5 \%)$ between the two protocols, which suggest that the graded exercise protocol has a high inter-method reliability. However, despite a small bias (-3\% points of $\mathrm{VO}_{2 \max }$ ) between the two protocols in determination of $\mathrm{Fat}_{\mathrm{Max}}$, considerable intra-individual variation ( $95 \%$ LoA -12 to $7 \%$ points of $\left.\mathrm{VO}_{2 \max }\right)$ and a trend $(\mathrm{p}=0.06)$ towards systematic difference reveal that further optimization of the graded exercise protocol is needed to improve validity.

\section{Validity and inter-method reliability of the graded exercise protocol for determination of Fat Max $_{\text {in }}$}

\section{individuals with obesity}

The overall aim was to develop a graded exercise protocol, which could accurately determine Fat Max $_{\text {in }}$ individuals with obesity. Importantly, the validity of the graded exercise protocol should be judged in the context of existing protocols for determination of Fat ${ }_{\text {Max. }}$ Achten et al. (Achten et al. 2002; Achten and Jeukendrup 2003) conducted the only other study validating a graded exercise protocol against a continuous exercise protocol. In contrast to the present study, the protocol validated by Achten et al. was for well-trained, and differences in the results may relate to differences in e.g. aerobic capacity and degree of adiposity. Based on the fact that there was no systematic difference between the graded 
and the continuous protocol, Achten et al. concluded that their graded exercise protocol could

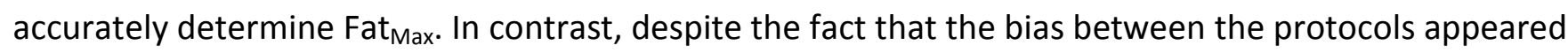
similar or smaller in the present study $\left(42 \pm 2\right.$ vs $45 \pm 2 \%$ point of $\left.\mathrm{VO}_{2 \max }\right)(\mathrm{SEM})$ compared to Achten et al. ( $56 \pm 3$ vs $58 \pm 3 \%$ and $64 \pm 3 \%$ point of $\mathrm{VO}_{2 \max }$ ) we observed a tendency towards a systematic difference in Fat $_{\text {Max. }}$ A possible explanation for the divergent findings is lower measurement variation in the present study, which makes it easier to detect a difference. It is likely that also a difference in the number of comparisons made in the statistical analysis contribute to the different result ( 2 vs. 3 comparisons). Albeit not significant, Achten et al. also observed Fat Max $_{\text {at }}$ a higher relative intensity with the continuous compared to the graded exercise protocol. In addition to assessing systematic differences between the two protocols in the present study, the inter-method reliability was determined by Pearson correlation coefficients, ICC and within subject CV. A strong relationship and a low CV was observed, which indicate that the graded exercise protocol has a high inter-method reliability.

To investigate the validity and to evaluate the practical use of the graded exercise protocol intraindividual variation was visualized (Bland Altman plot) and calculated. The improvements (3-15\% points of $\mathrm{VO}_{2 \max }$ ) reported in Fat $\mathrm{Max}_{\text {ax }}$ after aerobic training periods of 10 to 12 weeks (Mogensen et al. 2009; Nordby et al. 2015; Rosenkilde et al. 2015) are generally smaller than the 95\% LoA (-12 to $7 \%$ point of $\mathrm{VO}_{2 \mathrm{max}}$ ) reported in the present study, and by others (Meyer et al. 2009; Croci et al. 2014a). Thus, the graded exercise protocol is not suitable for assessment of individual changes in Fat Max $_{\text {after }}$ e.g. a shorter intervention. However, the graded exercise protocol might be used for comparisons of means across larger groups, where the intra-individual variation in Fat ${ }_{\mathrm{Max}}$ is accounted for in a powercalculation. 
Day-to-day reliability was only determined in normal weight individuals and not in obese, which is a

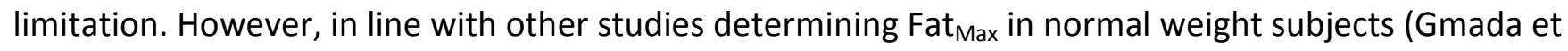
al. 2012; De Souza Silveira et al. 2016; Stoa et al. 2016) ICC and Pearson correlation coefficients between the two tests were excellent $(0.81$ and 0.82$)$ for Fat ${ }_{\text {Max }}$, within subject CV were low $(3 \%)$, and no systematic differences were observed. Furthermore, the 95\% LoA (-8 and $11 \%$ point of $\mathrm{VO}_{2 \max }$ ) between the two graded tests as determined by Bland Altman plot was also similar to what has been reported by others (Meyer et al. 2009; Croci et al. 2014a). Thus, the graded exercise protocol appears as reliable (day-to-day) as other protocols in determining Fat ${ }_{\text {Max }}$ in normal weight subjects (Meyer et al. 2009; Croci et al. 2014b). It should, however, be noted, that the magnitude of the 95\% LoA between the graded and the SCE protocol in the obese in the present study was similar to the 95\% LoA in the normal weight individuals performing the graded exercise protocol at two different occasions.

\section{Factors contributing to variation in Fat Max}

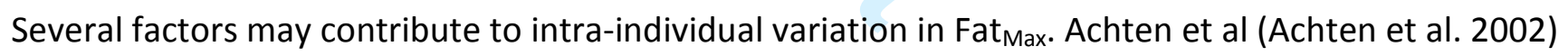
concluded that 3-min. steps and increments of 35 watts were appropriate for well-trained subjects in order to reach steady-state, and that 4-6 steps was necessary to construct a fat oxidation curve with a good fit. Bordenave et al. recommended steps longer than 3-min in sedentary individuals as fat oxidation could otherwise be overestimated (Bordenave et al. 2007). In the present study, it could be speculated that the 3-min steps in the graded exercise protocol were too short for the obese to reach steady-state. To control this, data on $\mathrm{VO}_{2}$ and $\mathrm{VCO}_{2}$ from 2.00-2.30 and from 2.30-3.00 at each step were compared (Supplementary Table S1). No difference was observed for $\mathrm{VO}_{2}$. Although, the maximal mean difference in $\mathrm{VCO}_{2}$ was only $4 \mathrm{ml}$, a trend towards higher $\mathrm{VCO}_{2}$ from 2.30-3.00 compared to 2.002.30 was observed indicating that the obese subjects were only approaching steady-state. The optimal 
way to control, whether the subjects were in steady-state from 2.30-3.00 would have been to compare two graded exercise protocols with 3-min and 4-min steps, respectively. The study was, however, not designed to do that, and that is a limitation and consequently fat oxidation may have been overestimated. However, adding one extra min to each step would have extended the total length of the protocol with 5-6 min, which in these subjects could also have affected $\mathrm{VO}_{2}$ and $\mathrm{VCO}_{2}$, especially at the last steps.

The graded exercise protocol was verified against a SCE protocol, in which Fat Max $_{\text {was determined from }}$ rest and continuous exercise at 35, 50 and $65 \%$ of $\mathrm{VO}_{2 \max }$ (interspersed by 45 min breaks). The 10-min exercise periods were distributed over $2 \frac{1}{2}$ hours on the same day. An alternative would have been to distribute the exercise periods on different days as it was done in the original study by Achten et al. The advantage of our approach was a minimized day-to-day variation in Fat $\mathrm{Max}_{\text {(experiments on two }}$ days only). It was recently shown that standardizing the diet and physical activity several days prior to

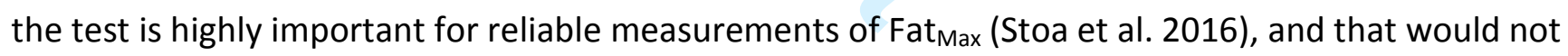
have been easy with continuous exercise on 3-4 different days. With 2-3 days between each test day, the test period would disperse over a total of 10-15 days. On the other hand it cannot be excluded that fat oxidation during the two last 10-min exercise periods during the SCE protocol was affected by the prior steps. Blood samples were taken before initiation of exercise at 35,50 and $65 \%$ of $\mathrm{VO}_{2 \max }$ to retrospectively check availability of plasma substrates. No systematic differences in the blood parameters investigated were observed (Table 3). However, there were large intra-individuals differences in especially plasma concentrations of FFA and glycerol (Table 3, Figure $1 \mathrm{~g}$, h and Figure $2 \mathrm{~g}$, h), which probably influences the intra-individual variation observed in Fat Max $_{\text {and MFO. }}$. 
Fat oxidation was measured at rest and during exercise at three different intensities during the SCE protocol, which gives four points for the $2^{\text {nd }}$ degree polynomial regression used to determine MFO and Fat $_{\text {Max }}$. The SCE protocol was designed to obtain measurements of fat oxidation at both sides of MFO ( 35 and $65 \%$ of $\mathrm{VO}_{2 \max }$ ) and a measurement close to MFO $\left(50 \%\right.$ of $\left.\mathrm{VO}_{2 \max }\right)$. The average fit of the curve was $r^{2}=0.93$ for the SCE protocol, which is a very good fit. It is not clear how many different exercise intensities Achten et al. used in their continuous protocol. However, increasing the number of continuous exercise intensities in order to possibly attain a better fit and a more accurate determination of Fat $\mathrm{Max}_{\text {and }}$ MFO is indeed relevant. A $3^{\text {rd }}$ degree polynomial fit was also analyzed for each subject on the graded exercise protocol, and this resulted in slightly better fit $\left(r^{2}=0.93\right)$ compared to a $2^{\text {nd }}$ degree polynomial regression $\left(r^{2}=0.90\right)$. However, no difference in Fat ${ }_{\text {Max }}$ and MFO was observed between the $2^{\text {nd }}$ and $3^{\text {rd }}$ degree polynomial regression (Fat Max $_{\text {: }} 42(39-46)$ vs. 42 (37-47)\% of $\mathrm{VO}_{2 \max }, \mathrm{MFO}: 0.33(0.29-0.37)$ vs. $\left.0.34(0.30-0.39) \mathrm{g} \mathrm{min}^{-1}\right)$.

Albeit weak, resting concentration of plasma FFA ( $r=-0.53, p<0.05)($ Rosenkilde et al. 2010), and levels of plasma FFA and glycerol during exercise at Fat ${ }_{\operatorname{Max}}(r=0.27, p=0.03, r=0.39, p=0.03)$ correlated with MFO (Robinson et al. 2016). Thus, measuring availability of plasma metabolites such as plasma FFA and glycerol seem relevant in studies investigating validity and reliability of Fat ${ }_{\text {Max }}$ and MFO. Within subject CV's between the two test days in fasting concentrations of FFA and glycerol were high (9-22\%) for

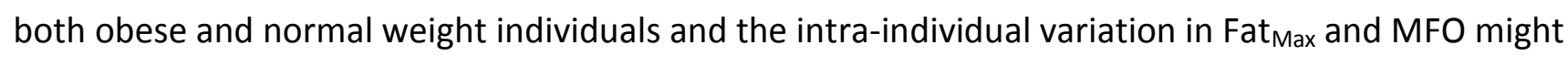
reflect that. In line with the present study Lanzi et al. (Lanzi et al. 2014) observed higher availability of FFA in obese compared to lean, and also suggested that obese might have an impaired muscular capacity to oxidize FFA. On the other hand it was also shown that levels of FFA, fat mass and insulin resistance does not follow hand in hand as e.g. women have higher levels of FFA compared to men, 
and at the same time they are more insulin sensitive (Karpe et al. 2011). Regulation of fat oxidation is complex; however, a step towards finding an optimal graded exercise test for determination of Fat Max and MFO may involve measurement of fasting and exercise levels of plasma substrates.

In summary, for the first time a graded exercise protocol for determination of Fat ${ }_{\text {Max }}$ in individuals with obesity was developed, validated and inter-method reliability tested against Fat ${ }_{\text {Max }}$ determined from control measurements of fat oxidation at rest and during continuous exercise. There was a high to excellent correlation and a low CV between the two protocols in determination of Fat ${ }_{\text {Max }}$, which suggest that the graded exercise protocol has a high inter-method reliability. However, considerable intra-individual variation and a trend towards systematic difference reveal that further optimization of the graded exercise protocol is needed to improve validity.

\section{Acknowledgements}

All subjects are thanked for participation in the study. Thomas Bech and Jeppe Bach (Xlab, Center of Healthy Aging, Department of Biomedical Sciences, Faculty of Health Sciences, University of Copenhagen, Denmark) are thanked for expert technical assistance.

\section{Funding}

The Nordea Foundation (Copenhagen, Denmark) and the research program "Physical activity and nutrition for improvement of health" funded by the University of Copenhagen Excellence Program for Interdisciplinary Research and Center of Healthy Aging. The funds were not involved in any part of the study except from financial support.

\section{Author contribution}


JWH, SD and SL designed the study. SD, SL, CBP, SDS, CS, FD and JWH contributed to data acquisition, analyses and interpretation. SD wrote the manuscript. All authors revised the manuscript and approved the final article.

\section{Conflicts of interests}

The authors declare no conflict of interests 


\section{Reference List}

Achten, J., Gleeson, M., and Jeukendrup, A.E. 2002. Determination of the exercise intensity that elicits maximal fat oxidation. Med. Sci. Sports Exerc. 34: 92-97. PMID:11782653

Achten, J. and Jeukendrup, A.E. 2003. Maximal fat oxidation during exercise in trained men. Int. J. Sports Med. 24: 603-608. doi:10.1055/s-2003-43265. PMID:14598198

Ara, I., Larsen, S., Stallknecht, B., Guerra, B., Morales-Alamo, D., Andersen, J.L., Ponce-Gonzalez, J.G., Guadalupe-Grau, A., Galbo, H., Calbet, J.A., and Helge, J.W. 2011. Normal mitochondrial function and increased fat oxidation capacity in leg and arm muscles in obese humans. Int. J. Obes. (Lond) 35: 99-108. doi:10.1038/ijo.2010.123. PMID:20548301

Bergman, B.C. and Brooks, G.A. 1999. Respiratory gas-exchange ratios during graded exercise in fed and fasted trained and untrained men. J. Appl. Physiol. (1985) 86: 479-487. PMID:9931180

Bordenave, S., Flavier, S., Fedou, C., Brun, J.F., and Mercier, J. 2007. Exercise calorimetry in sedentary patients: procedures based on short 3 min steps underestimate carbohydrate oxidation and overestimate lipid oxidation. Diabetes. Metab. 33: 379-384. doi:10.1016/j.diabet.2007.04.003. PMID:17936665 Croci, I., Borrani, F., Byrne, N.M., Wood, R.E., Hickman, I.J., Cheneviere, X., and Malatesta, D. 2014 a. Reproducibility of Fatmax and fat oxidation rates during exercise in recreationally trained males. PLoS One 9: e97930. doi:10.1371/journal.pone.0097930. PMID:24886715

Croci, I., Byrne, N.M., Choquette, S., Hills, A.P., Chachay, V.S., Clouston, A.D., O'Moore-Sullivan, T.M., Macdonald, G.A., Prins, J.B., and Hickman, I.J. 2013. Whole-body substrate metabolism is associated with disease severity in patients with non-alcoholic fatty liver disease. Gut. 62: 1625-1633. doi:10.1136/gutjnl-2012-302789. PMID:23077135

Croci, I., Hickman, I.J., Wood, R.E., Borrani, F., Macdonald, G.A., and Byrne, N.M. 2014b. Fat oxidation over a range of exercise intensities: fitness versus fatness. Appl. Physiol. Nutr. Metab. 39: 1352-1359. doi:10.1139/apnm-2014-0144. PMID:25356842

De Souza Silveira, R., Carlsohn, A., Langen, G., Mayer, F., and Scharhag-Rosenberger, F. 2016. Reliability and day-to-day variability of peak fat oxidation during treadmill ergometry. J. Int. Soc. Sports Nutr. 13: 4. doi:10.1186/s12970-016-0115-1. PMID:26816497

Fleiss, J. 1986. The Design and Analysis of Clinical Experiments. New York: John Wiley \& Sons. Frayn, K.N. 1983. Calculation of substrate oxidation rates in vivo from gaseous exchange. J. Appl. Physiol. Respir. Environ. Exerc. Physiol. 55: 628-634. PMID:6618956

Gmada, N., Marzouki, H., Haboubi, M., Tabka, Z., Shephard, R.J., and Bouhlel, E. 2012. Crossover and maximal fat-oxidation points in sedentary healthy subjects: methodological issues. Diabetes. Metab. 38: 40-45. doi:10.1016/j.diabet.2011.07.004. PMID:21944864

Ipavec-Levasseur, S., Croci, I., Choquette, S., Byrne, N.M., Cowin, G., O'Moore-Sullivan, T.M., Prins, J.B., and Hickman, I.J. 2015. Effect of 1-h moderate-intensity aerobic exercise on intramyocellular lipids in obese men before and after a lifestyle intervention. Appl. Physiol. Nutr. Metab. 40: 1262-1268. doi:10.1139/apnm-2015-0258. PMID:26575100

Karpe, F., Dickmann, J.R., and Frayn, K.N. 2011. Fatty acids, obesity, and insulin resistance: time for a reevaluation. Diabetes 60: 2441-2449. doi:10.2337/db11-0425. PMID:21948998

Lanzi, S., Codecasa, F., Cornacchia, M., Maestrini, S., Salvadori, A., Brunani, A., and Malatesta, D. 2014. Fat oxidation, hormonal and plasma metabolite kinetics during a submaximal incremental test in lean and obese adults. PLoS One 9: e88707. doi:10.1371/journal.pone.0088707. PMID:24523934 Meyer, T., Folz, C., Rosenberger, F., and Kindermann, W. 2009. The reliability of fat. Scand. J. Med. Sci. Sports 19: 213-221. doi:10.1111/j.1600-0838.2008.00775.x. PMID:18282220 
Mogensen, M., Vind, B.F., Hojlund, K., Beck-Nielsen, H., and Sahlin, K. 2009. Maximal lipid oxidation in patients with type 2 diabetes is normal and shows an adequate increase in response to aerobic training. Diabetes Obes. Metab. 11: 874-883. doi:10.1111/j.1463-1326.2009.01063.x. PMID:19531056 Nordby, P., Rosenkilde, M., Ploug, T., Westh, K., Feigh, M., Nielsen, N.B., Helge, J.W., and Stallknecht, B. 2015. Independent effects of endurance training and weight loss on peak fat oxidation in moderately overweight men: a randomized controlled trial. J. Appl. Physiol. (1985) 118: 803-810. doi:10.1152/japplphysiol.00715.2014. PMID:25614598

Robinson, S.L., Chambers, E.S., Fletcher, G., and Wallis, G.A. 2016. Lipolytic Markers, Insulin and Resting Fat Oxidation are Associated with Maximal Fat Oxidation. Int. J. Sports Med. 37: 607-613. doi:10.1055/s-0042-100291. PMID:27116342

Romijn, J.A., Coyle, E.F., Sidossis, L.S., Gastaldelli, A., Horowitz, J.F., Endert, E., and Wolfe, R.R. 1993. Regulation of endogenous fat and carbohydrate metabolism in relation to exercise intensity and duration. Am. J. Physiol. 265: E380-391. PMID:8214047

Romijn, J.A., Coyle, E.F., Sidossis, L.S., Rosenblatt, J., and Wolfe, R.R. 2000. Substrate metabolism during different exercise intensities in endurance-trained women. J. Appl. Physiol. (1985) 88: 17071714. PMID:10797133

Rosenkilde, M., Nordby, P., Nielsen, L.B., Stallknecht, B.M., and Helge, J.W. 2010. Fat oxidation at rest predicts peak fat oxidation during exercise and metabolic phenotype in overweight men. Int. J. Obes. (Lond) 34: 871-877. doi:10.1038/ijo.2010.11. PMID:20157319

Rosenkilde, M., Reichkendler, M.H., Auerbach, P., Bonne, T.C., Sjodin, A., Ploug, T., and Stallknecht, B.M. 2015. Changes in peak fat oxidation in response to different doses of endurance training. Scand. J. Med. Sci. Sports 25: 41-52. doi:10.1111/sms.12151. PMID:24350597

Sidossis, L.S., Gastaldelli, A., Klein, S., and Wolfe, R.R. 1997. Regulation of plasma fatty acid oxidation during low- and high-intensity exercise. Am. J. Physiol. 272: E1065-1070. PMID:9227453 Stoa, E.M., Nyhus, L.K., Borresen, S.C., Nygaard, C., Hovet, A.M., Bratland-Sanda, S., Helgerud, J., and Storen, O. 2016. Day to day variability in fat oxidation and the effect after only 1 day of change in diet composition. Appl. Physiol. Nutr. Metab. 41: 397-404. doi:10.1139/apnm-2015-0334. PMID:26960444

Tan, S., Wang, J., and Cao, L. 2016a. Exercise training at the intensity of maximal fat oxidation in obese boys. Appl. Physiol. Nutr. Metab. 41: 49-54. doi:10.1139/apnm-2015-0174. PMID:26701116

Tan, S., Wang, J., Cao, L., Guo, Z., and Wang, Y. 2016b. Positive effect of exercise training at maximal fat oxidation intensity on body composition and lipid metabolism in overweight middle-aged women. Clin. Physiol. Funct. Imaging 36: 225-230. doi:10.1111/cpf.12217. PMID:27072372

Thompson, D.L., Townsend, K.M., Boughey, R., Patterson, K., and Bassett, D.R., Jr. 1998. Substrate use during and following moderate- and low-intensity exercise: implications for weight control. Eur. J. Appl. Physiol. Occup. Physiol. 78: 43-49. PMID:9660155

Van Aggel-Leijssen, D.P., Saris, W.H., Hul, G.B., and Van Baak, M.A. 2002. Long-term effects of lowintensity exercise training on fat metabolism in weight-reduced obese men. Metabolism 51: 1003-1010. PMID:12145773

Venables, M.C., Achten, J., and Jeukendrup, A.E. 2005. Determinants of fat oxidation during exercise in healthy men and women: a cross-sectional study. J. Appl. Physiol. (1985) 98: 160-167.

doi:10.1152/japplphysiol.00662.2003. PMID:15333616

Venables, M.C. and Jeukendrup, A.E. 2008. Endurance training and obesity: effect on substrate metabolism and insulin sensitivity. Med. Sci. Sports Exerc. 40: 495-502.

doi:10.1249/MSS.0b013e31815f256f. PMID:18379212 
Wood, R.E., Hills, A.P., Hunter, G.R., King, N.A., and Byrne, N.M. 2010. Vo2max in overweight and obese adults: do they meet the threshold criteria? Med. Sci. Sports Exerc. 42: 470-477. doi:10.1249/MSS.0b013e3181b666ad. PMID:19952821 


\section{Tables}

Table 1 Subject characteristics

\begin{tabular}{|c|c|c|}
\hline & $\begin{array}{l}\text { Individuals } \\
\text { with obesity }\end{array}$ & $\begin{array}{c}\text { Individuals } \\
\text { with normal weight }\end{array}$ \\
\hline Gender (w/m) & $8 / 8$ & $3 / 5$ \\
\hline Age (years) & $28(26-29)$ & $32(30-34)$ \\
\hline Height $(\mathrm{cm})$ & $173(172-175)$ & 179 (160-199) \\
\hline Weight (kg) & $109(105-113)$ & 76 (73-79) \\
\hline Fat (\%) & $46(45-48)$ & $24(22-26)$ \\
\hline Fat (kg) & $49(46-52)$ & $17(15-20)$ \\
\hline FFM (kg) & $60(57-63)$ & $59(56-62)$ \\
\hline Waist circumference $(\mathrm{cm})$ & $109(106-112)$ & $85(83-87)$ \\
\hline $\operatorname{HbA1c}(\%)$ & $5.1(5.0-5.2)$ & $4.9(4.6-5.2)$ \\
\hline Hematocrit (\%) & $42(42-42)$ & $43(41-44)$ \\
\hline Hemoglobin $\left(\mathrm{mmol} \mathrm{mol}^{-1}\right)$ & $8.9(8.4-9.3)$ & $9.0(8-10)$ \\
\hline Systolic blood pressure (mmHg) & $120(117-122)$ & $128(126-131)$ \\
\hline Diastolic blood pressure $(\mathrm{mmHg})$ & $82(80-83)$ & $80(78-81)$ \\
\hline Resting heart rate (beats $\mathrm{min}^{-1}$ ) & $70(69-72)$ & $60(59-61)$ \\
\hline $\mathrm{VO}_{2 \max }\left(I \min ^{-1}\right)$ & $3.2(3.2-3.2)$ & $3.4(3.4-3.4)$ \\
\hline $\mathrm{VO}_{2 \max }\left(\mathrm{ml} \min ^{-1} \mathrm{~kg}^{-1}\right)$ & $29.8(28.2-31.4)$ & $45.2(44-47)$ \\
\hline $\mathrm{VO}_{2 \max }\left(\mathrm{ml} \mathrm{min}^{-1} \mathrm{FFM}^{-1}\right)$ & $54.2(52.8-55.5)$ & $58.4(57-60)$ \\
\hline $\mathrm{HR}_{\max }\left(\right.$ beats $\left.\min ^{-1}\right)$ & $184(178-191)$ & $174(164-184)$ \\
\hline
\end{tabular}

Descriptive data of subjects included in the study. Data are presented as means with $95 \%$ confidence intervals. 


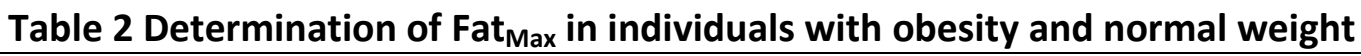

\begin{tabular}{|c|c|c|c|c|c|c|}
\hline Individuals with obesity & $\begin{array}{l}\text { Graded } \\
\text { protocol }\end{array}$ & SCE protocol & $\begin{array}{l}\text { Pearson correlation } \\
\text { coefficient ( } r, p \text {-value) }\end{array}$ & $\begin{array}{c}\text { Intraclass correlation } \\
\text { coefficient }\end{array}$ & CV (\%) & $\begin{array}{l}\text { Paired t-test } \\
\text { (p-value) }\end{array}$ \\
\hline MFO $\left(\mathrm{g} \mathrm{min}^{-1}\right)$ & $0.33(0.29-0.37)$ & $0.29(0.26-0.32)$ & $0.56,0.03$ & 0.48 & $11(8-15)$ & 0.03 \\
\hline $\mathrm{Fat}_{\operatorname{Max}}\left(\% \mathrm{VO}_{2 \max }\right)$ & $42.1(38.5-45.7)$ & $44.6(42.5-46.7)$ & $0.75,<0.001$ & 0.72 & $5(3-7)$ & 0.06 \\
\hline Watt at Fat ${ }_{\text {Max }}$ (Watt) & $69.8(65.4-74.2)$ & $78.8(74.3-83.3)$ & $0.91,<0.001$ & 0.81 & $6(3-10)$ & $<0.01$ \\
\hline $\mathrm{VO}_{2}$ at $\mathrm{Fat}_{\mathrm{Max}}\left(\mathrm{I} \mathrm{min}^{-1}\right)$ & $1.34(1.33-1.34)$ & $1.43(1.42-1.44)$ & $0.83,<0.001$ & 0.79 & $5(3-7)$ & 0.03 \\
\hline $\mathrm{VCO}_{2}$ at $\mathrm{Fat}_{\mathrm{Max}}\left(\mathrm{I} \mathrm{min}^{-1}\right)$ & $1.19(1.18-1.20)$ & $1.30(1.29-1.31)$ & $0.83,<0.001$ & 0.74 & $5(3-8)$ & 0.01 \\
\hline$V_{E}$ at $\operatorname{Fat}_{\operatorname{Max}}\left(I \min ^{-1}\right)$ & $33.4(30.8-36.0)$ & 37.6 (35.3-39.9) & $0.84,<0.001$ & 0.74 & $7(3-10)$ & $<0.01$ \\
\hline$H R$ at $F t_{\operatorname{Max}}\left(\right.$ beat $\left.\min ^{-1}\right)$ & $117(114-119)$ & $121(119-123)$ & $0.72<0.01$ & 0.70 & $4(2-6)$ & 0.14 \\
\hline $\begin{array}{l}\text { Normal weight } \\
\text { individuals }\end{array}$ & $\begin{array}{c}\text { Graded } \\
\text { protocol } 1\end{array}$ & $\begin{array}{c}\text { Graded } \\
\text { protocol } 2\end{array}$ & $\begin{array}{l}\text { Pearson correlation } \\
\text { coefficient ( } r, p \text {-value) }\end{array}$ & $\begin{array}{c}\text { Intraclass correlation } \\
\text { coefficient }\end{array}$ & CV (\%) & $\begin{array}{l}\text { Paired t-test } \\
\text { (p-value) }\end{array}$ \\
\hline MFO $\left(\mathrm{g} \mathrm{min}^{-1}\right)$ & $0.31(0.25-0.38)$ & $0.31(0.23-0.40)$ & $0.57,0.01$ & 0.58 & $11(6-17)$ & 0.98 \\
\hline $\mathrm{Fat}_{\mathrm{Max}}\left(\% \mathrm{VO}_{2 \max }\right)$ & $42.3(40.1-44.4)$ & $40.9(38.7-43.1)$ & $0.81,<0.001$ & 0.82 & $3(0-7)$ & 0.44 \\
\hline Watt at Fat $_{\text {Max }}$ (Watt) & $65.2(57.4-73.1)$ & $64.7(56.4-73.1)$ & $0.94,<0.001$ & 0.92 & $5(1-9)$ & 0.94 \\
\hline $\mathrm{VO}_{2}$ at $\mathrm{Fat}_{\mathrm{Max}}\left(\mathrm{I} \mathrm{min}^{-1}\right)$ & $1.40(1.38-1.42)$ & $1.39(1.37-1.41)$ & $0.87,<0.001$ & 0.83 & $4(0-9)$ & 0.85 \\
\hline $\mathrm{VCO}_{2}$ at $\mathrm{Fat}_{\mathrm{Max}}\left(\mathrm{I} \mathrm{min}^{-1}\right)$ & $1.09(1.07-1.12)$ & $1.09(1.06-1.12)$ & $0.87,<0.001$ & 0.94 & $4(1-8)$ & 0.97 \\
\hline$V_{E}$ at $F t_{\operatorname{Max}}\left(I \min ^{-1}\right)$ & $34.7(32.5-36.9)$ & $35.0(32.2-37.9)$ & $0.87,<0.001$ & 0.86 & $5(1-9)$ & 0.93 \\
\hline $\mathrm{HR}$ at Fat ${ }_{\text {Max }}$ (beat $\mathrm{min}^{-1}$ ) & $105(101-108)$ & $101(98-104)$ & $0.97,<0.001$ & 0.94 & $2(0-3)$ & 0.18 \\
\hline $\mathrm{VO}_{2 \max }\left(I \min ^{-1}\right)$ & $3.42(3.40-3.44)$ & $3.40(3.38-3.42)$ & $0.98,<0.001$ & 0.99 & $1(0-2)$ & 0.62 \\
\hline $\mathrm{HR}_{\max }$ & 175 (173-176) & $173(171-175)$ & $0.97,<0.001$ & 0.97 & $1(0-2)$ & 0.21 \\
\hline
\end{tabular}

SCE: Short continuous exercise, $\mathrm{VO}_{2}$ : oxygen uptake, $\mathrm{VCO}_{2}$ : expired carbon dioxide, $\mathrm{V}_{\mathrm{E}}$ : lung ventilation, $\mathrm{HR}$ : heart rate. Individuals with obesity completed a graded exercise protocol, and 10-min rest and continuous exercise periods on two different days. Normal weight individuals completed the graded exercise protocol at two different days. Fat oxidations were plotted against exercise

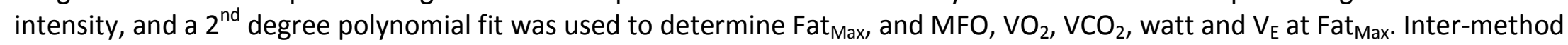
(obese subjects) or day-to-day (normal weights subjects) reliability, variability and systematic differences were analyzed by Pearson correlation coefficient, intraclass correlation coefficient, within subject coefficient of variation (CV) and paired t-test. Data are means $\pm 95 \%$ confidence intervals. 
Table 3 Levels of plasma lipids, substrates and hormones in individuals with obesity and normal weight

\begin{tabular}{|c|c|c|c|c|c|c|c|c|}
\hline $\begin{array}{l}\text { Individuals with } \\
\text { obesity }\end{array}$ & $\begin{array}{c}\text { Graded } \\
\text { protocol (pre) }\end{array}$ & $\begin{array}{c}\text { SCE protocol } \\
\text { (pre } 35 \% \text { of } \\
\text { vO }_{2 \max } \text { ) }\end{array}$ & $\begin{array}{c}\text { CV } \\
\text { (Graded vs } \\
\text { SCE } \\
\text { protocol) } \\
(\%)\end{array}$ & $\begin{array}{l}\text { Paired t-test } \\
\text { (Graded vs } \\
\text { SCE } \\
\text { protocol) (p- } \\
\text { value) }\end{array}$ & $\begin{array}{l}\text { SCE protocol } \\
\text { (pre } 50 \% \text { of } \\
\text { VO }_{2 \max } \text { ) }\end{array}$ & $\begin{array}{l}\text { SCE protocol } \\
\text { (pre } 65 \% \text { of } \\
\text { VO }_{2 \max } \text { ) }\end{array}$ & $\begin{array}{c}\text { CV (Pre 35\%, } \\
50 \% \text { and } \\
65 \% \text { in SCE } \\
\text { protocol) } \\
(\%)\end{array}$ & $\begin{array}{c}\text { One-Way } \\
\text { ANOVA (Pre } \\
35 \%, 50 \% \text { and } \\
65 \% \text { in SCE } \\
\text { protocol) (p- } \\
\text { value) }\end{array}$ \\
\hline FFA $\left(\mu \mathrm{mol} \mathrm{I}^{-1}\right)$ & 473 (387-559) & $465(370-560)$ & $13(8-19)$ & 0.81 & $465(381-548)$ & $510(410-611)$ & $12(11-20)$ & 0.70 \\
\hline Glycerol $\left(\mu \mathrm{mol} \mathrm{I}^{-1}\right)$ & $79(68-90)$ & $76(67-84)$ & $9(5-13)$ & 0.70 & $62(57-67)$ & $65(61-70)$ & $14(12-20)$ & 0.29 \\
\hline Glucose $\left(\mathrm{mmol} \mathrm{I}^{-1}\right)$ & $5.4(5.1-5.8)$ & $5.3(4.9-5.8)$ & $3(1-4)$ & 0.18 & $5.3(4.9-5.7)$ & $5.3(5.1-5.6)$ & $3(2-4)$ & 0.98 \\
\hline Insulin $\left(\mathrm{pmol} \mathrm{I}{ }^{-1}\right)$ & $74(60-87)$ & $88(74-102)$ & $14(7-20)$ & 0.07 & 80 (64-95) & $73(61-85)$ & $14(12-24)$ & 0.93 \\
\hline Lactate $\left(\mathrm{mmol} \mathrm{I}^{-1}\right)$ & $0.9(0.7-1.0)$ & $0.9(0.8-1.1)$ & $12(7-17)$ & 0.60 & $0.9(0.8-1.1)$ & $0.8(0.7-1.0)$ & $12(12-19)$ & 0.44 \\
\hline $\begin{array}{l}\text { Normal weight } \\
\text { individuals }\end{array}$ & $\begin{array}{c}\text { Graded } \\
\text { protocol } \\
1 \text { (pre) }\end{array}$ & $\begin{array}{c}\text { Graded } \\
\text { protocol } 2 \\
\text { (pre) }\end{array}$ & $\begin{array}{c}\mathrm{CV} \\
\text { (Graded vs } \\
\text { SCE } \\
\text { protocol) } \\
(\%) \\
\end{array}$ & $\begin{array}{l}\text { Paired t-test } \\
\text { (Graded vs } \\
\text { SCE protocol } \\
\text { (p-value) }\end{array}$ & & & & \\
\hline FFA $\left(\mu \mathrm{mol} \mathrm{I}^{-1}\right)$ & $246(237-255)$ & $239(224-254)$ & $22(11-32)$ & 0.88 & - & - & - & - \\
\hline Glycerol $\left(\mu \mathrm{mol} \mathrm{I}^{-1}\right)$ & $38(35-41)$ & 45 (41-49) & $14(5-23)$ & 0.24 & - & - & - & - \\
\hline Glucose $\left(\mathrm{mmol}^{-1}\right)$ & $5.5(5.0-5.9)$ & $5.3(4.7-5.9)$ & $3(0-7)$ & 0.58 & - & - & - & - \\
\hline Insulin $\left(\mathrm{pmol} \mathrm{I}^{-1}\right)$ & $16(11-21)$ & $17(11-22)$ & $22(7-37)$ & 0.87 & - & - & - & - \\
\hline Lactate $\left(\mathrm{mmol} \mathrm{I}^{-1}\right)$ & $0.9(0.8-1.0)$ & $0.7(0.6-0.9)$ & $21(9-32)$ & 0.83 & - & - & - & - \\
\hline
\end{tabular}

Plasma concentrations of lipids, metabolites and hormones before initiation of the graded exercise protocol and 10-min continuous exercise at 35,50 and $65 \%$ of $\mathrm{VO}_{2 \max }$. The order of the continuous exercise periods were randomized, except that the first intensity always was $35 \%$ of $\mathrm{VO}_{2 \max }$. The 10 -min continuous exercise periods were separated by $45 \mathrm{~min}$. breaks in order to return to resting conditions before initiation of the next exercise period. SCE: Short continuous exercise, FFA: free fatty acids, CV: within subject coefficient of variation. Data are presented as means $\pm 95 \%$ confidence intervals. 


\section{Figure legends}

\section{Figure 1}

Fat oxidation (a), oxygen uptake $\left(\mathrm{VO}_{2}\right)(\mathbf{b})$, expired carbon dioxide $\left(\mathrm{VCO}_{2}\right)(\mathrm{c})$ and lung ventilation $\left(\mathrm{V}_{\mathrm{E}}\right)$ (d) are plotted against exercise intensity $\left(\% \mathrm{VO}_{2 \max }\right)$ for the graded and the short continuous exercise (SCE) protocols, respectively. Bland-Altman plot of the agreement in maximal fat oxidation (MFO) determined with the graded and the SCE protocol (e). Bland-Altman plot of the agreement in the intensity that elicits maximal fat oxidation (Fat ${ }_{M a x}$ ) determined with the graded and the SCE protocol (f). Women are indicated by squares and men by circles. Individual plasma concentrations of free fatty acids (FFA) (g) and glycerol (h). $n=15$ individuals with obesity. Data are mean with $\pm 95 \%$ confidence intervals.

\section{Figure 2}

Fat oxidation (a), oxygen uptake $\left(\mathrm{VO}_{2}\right)(\mathbf{b})$, expired carbon dioxide $\left(\mathrm{VCO}_{2}\right)(\mathrm{c})$ and lung ventilation $\left(\mathrm{V}_{\mathrm{E}}\right)$ (d) are plotted against exercise intensity $\left(\% \mathrm{VO}_{2 \max }\right)$ for the two graded exercise tests. Bland-Altman plot of the agreement in maximal fat oxidation (MFO) determined with the two graded exercise tests (e). Bland-Altman plot of the agreement in the intensity that elicits maximal fat oxidation (Fat Max $_{\text {) }}$ determined with the two graded exercise test $(\mathbf{f})$. Women are indicated by squares and men by circles. Individual plasma concentrations of free fatty acids (FFA) (g) and glycerol (h). $n=8$ individuals with normal weight. Data are mean with $\pm 95 \%$ confidence intervals. 

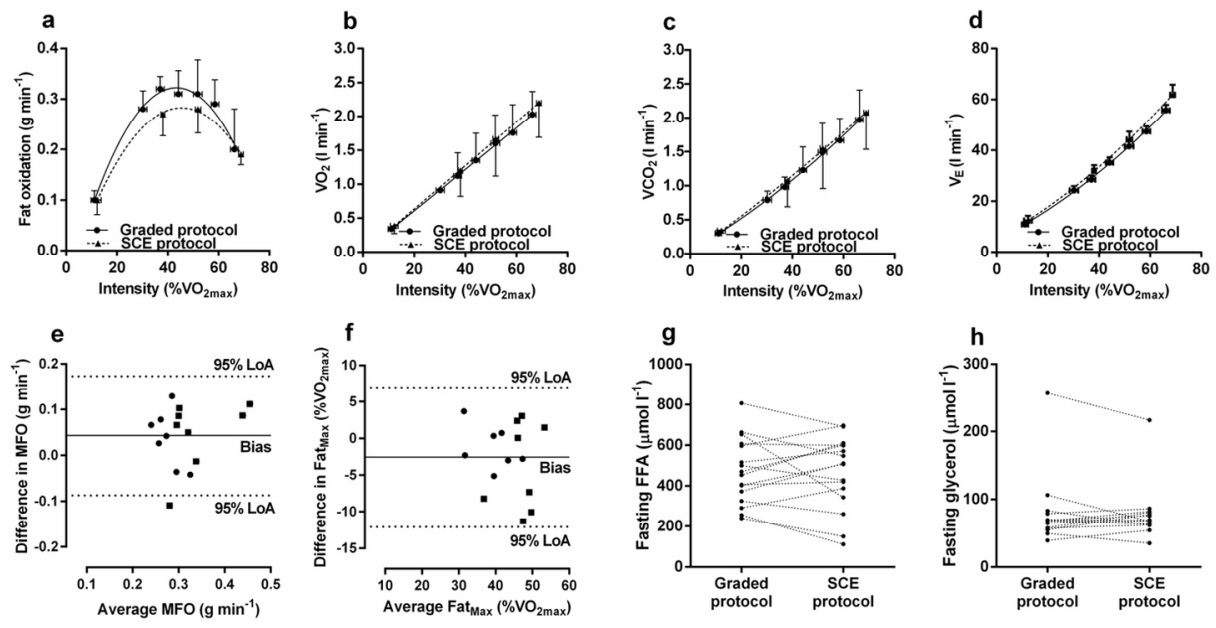

Figure 1

$134 \times 69 \mathrm{~mm}(300 \times 300 \mathrm{DPI})$ 

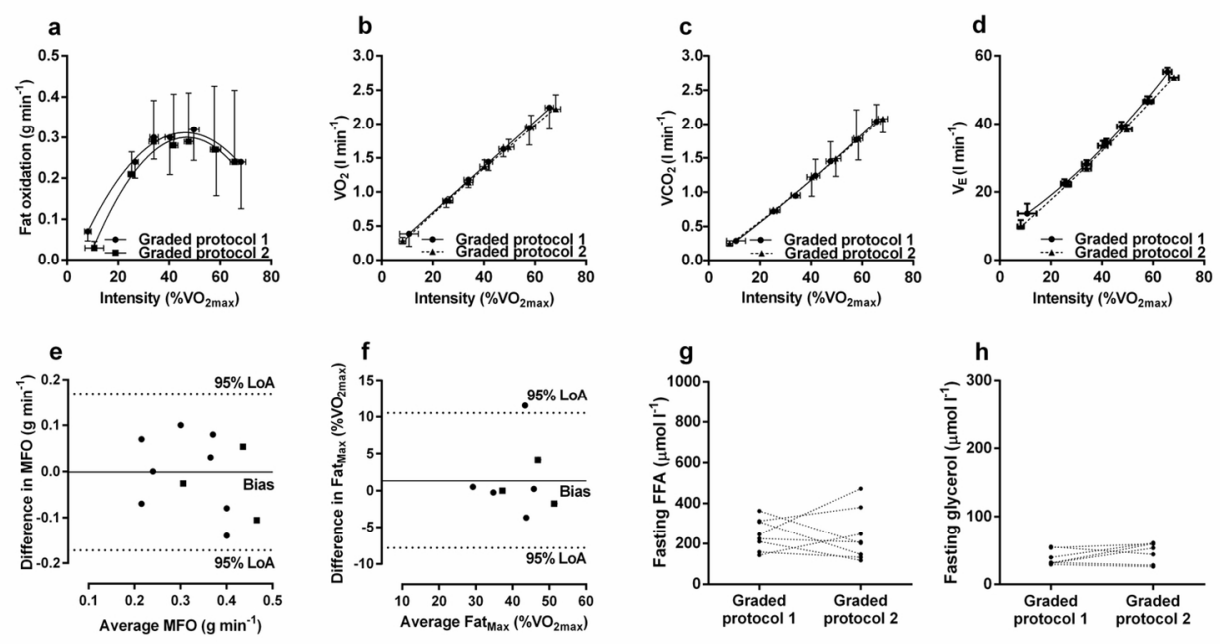

Figure 2

$134 \times 69 \mathrm{~mm}(300 \times 300 \mathrm{DPI})$ 